\title{
Germination and performance of seven native wildflowers in the Mediterranean landscape plantings
}

\author{
Enrico Scarici, Roberto Ruggeri, Maria Elena Provenzano, Francesco Rossini \\ Department of Agriculture and Forestry Sciences, University of Tuscia, Viterbo, Italy
}

\begin{abstract}
The use of native species in landscape design is a choice related to environmental sustainability and it contributes to the aesthetic appeal of urban and marginal areas. However, to date, the lack of knowledge of the ecological characteristics and agronomic practices of these species, represents a limit for their use. This study aims to obtain information about germination ecology, morphological traits and ornamental value of 7 selected perennial native taxa, with potential use in meadows seed mixtures for the Mediterranean environment. Seed germination for each taxon was assessed under different conditions (temperature, photoperiod and pre-treatment) in a controlled environment, while data on plant performances was collected from field plots. In general, the dormant seeds showed a positive response to pre-treatment with gibberellic acid $\left(\mathrm{GA}_{3}\right)$ and chilling within a period of about six months from the time of seed collection. The dependence of germination on light and temperature was observed in most of the tested taxa. Differences in plant height and flowering dynamics gave practical directions in terms of combining seeds of different species to create and maintain a wildflower meadow in low-maintenance areas. Crepis bursifolia L. and Hypochaeris radicata L. were the only two species, which showed good persistence during the two-year field study and met the aesthetic requirements of low-input Mediterranean landscaping. Our study by adding original findings to the limited knowledge available on wildflower sowing in the Mediterranean environment, contributes to the development of sustainable strategies in the greening projects designed for those peculiar climatic conditions.
\end{abstract}

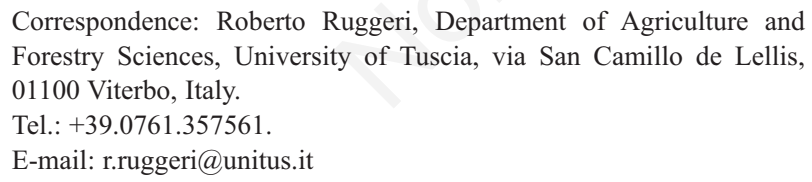

Key words: Herbaceous perennials; native plants; germination ecology; flowering dynamic; seed dormancy breaking.

Received for publication: 12 June 2017.

Revision received: 23 October 2017.

Accepted for publication: 23 October 2017.

(C) Copyright E. Scarici et al., 2018

Licensee PAGEPress, Italy

Italian Journal of Agronomy 2018; 13:1040

doi:10.4081/ija.2017.1040

This article is distributed under the terms of the Creative Commons Attribution Noncommercial License (by-nc 4.0) which permits any noncommercial use, distribution, and reproduction in any medium, provided the original author(s) and source are credited.

\section{Introduction}

The growing need to improve the quality of life in urban and marginal areas and to reduce the impact of management practices, is the driving force behind the researcher to focus on any form of sustainable greening, including wildflower meadows (Keller and Kollmann, 1999; Hitchmough, 2000; Braman et al., 2002). From this perspective, native species can represent valuable resources when considering their role in environmental sustainability, management cost reduction and local character preservation of urban and rural landscape (Florgård, 2000; Thomas and Schrock, 2004; Jongepierová et al., 2007; Bretzel et al., 2012, 2016). Native plants are generally well adapted to the local pedo-climatic conditions, since they have evolved over hundreds of years to thrive in the soil and in the climate of their original area and are expected to better adapt when used in landscaping projects (Worrell, 1992; Jones and Evans, 1994; Ruggeri et al., 2016). It is well known that some herbaceous native plants can quickly colonize poor soils, reduce erosion risk and the establishment of species with low ornamental value, as well as provide a natural pest control and an attractive roadside view (Forman and Alexander, 1998; Braman et al., 2002; Karim and Mallik, 2008; Bretzel et al., 2009). Moreover, they provide food and shelter to native wildlife, enhancing the local biodiversity and preserving the landscape identity (Kennedy and Southwood, 1984; Coleman et al., 2002; Slattery et al., 2003; Lindemann-Matthies and Bose, 2007). Particularly, the loss of natural areas due to increased population growth together with the use of invasive exotic species in landscaping, leads to a gradual change of places perception, depriving those of their uniqueness. Anyway, the native only policies in landscaping plantings have to be always contextualized, because there are exceptions where non-native species may play an important role (Kendle and Rose, 2000). In this regard, recent studies have found that using plants from one region of origin may not be the optimal strategy for providing resources for pollinators in an urban context (Salisbury et al., 2015; Hicks et al., 2016).

Italy has less than $3 \%$ of the European surface but supports the highest number of both animal and plant species within the European Union, as well as a high rate of endemism (Convention on Biological Diversity, 2013). Despite this richness, in our country the use of native herbaceous species in urban landscaping is very limited and not adequately promoted (Bretzel et al., 2009).

Particularly, in Italy land restoration studies have been mainly focused on the use of native shrubs and trees species (Nocentini, 1995; De Mei and Di Mauro, 2006). At the same time, even though the majority of native plants are well known and characterized from a botanical point of view (morphology, taxonomic identification, chorology, etc.), rare data are available on their seed germination ecology, phenology and cultivation techniques (Bretzel et al., 2016). Germination features and plant height are pivotal components of species' ecological strategy and contribute to their competitive ability (Schwinning and Weiner, 1998; Moles 
et al., 2009; Bretzel et al., 2012), as well as flowering which is the most relevant feature to determine the aesthetical perception of the meadow. Unlike other European countries, the lack of this type of knowledge is the reason why nurseries specialized in native plants propagation and a related market have not been developed in Italy and southern Europe yet.

Most of the spontaneous herbaceous plants could be easily propagated from seed, but many of them exhibit complex seed dormancy. Dormant seeds are quite common in nature, as dormancy plays an important role in the preservation of species (Baskin and Baskin, 2004a). Therefore, it is arguable that information on germination ecology and techniques to break dormancy is required for the propagation and cultivation of most wild native species (Baskin and Baskin, 2004b). However, information about germination requirements of most native species is unrefined or relatively unknown. Particularly, the lack of specific studies on rare and endemic species is due to several limitations such as their restricted geographic distribution, the difficulty in their identification and the absence of an economic interest.

The aim of this study was to investigate the potential of 7 native wildflower species for their use in sustainable landscape projects or in set-asides for ecological compensation sites in the Mediterranean environment. With this aim, seed germination ecology was studied in laboratory, while a field trial was set up to record emergence dynamics, morphometric parameters and ornamental value.

\section{Materials and methods}

\section{Plant material}

Ripe fruits were collected directly from eighty mother plants in the Northern area of the Latium Region (Central Italy) for a total of seven taxa: five belonging to Asteraceae family (Crepis bursifolia L., Hypochaeris radicata L., Picris hieracioides L., Reichardia picroides (L.) Roth, Tragopogon pratensis L.) and two to Lamiaceae (Marrubium vulgare L., Prunella laciniata (L.) L.). Selected species are hemicryptophytes typical of semi-arid environments (dry meadows, natural and semi-natural pasture habitats, waste lands, etc.) while, regarding their distribution range, two are Mediterranean ( $P$. laciniata and $R$. picroides), three are European (H. radicata, $P$. hieracioides and $T$. pratensis), one is widely distributed ( $M$. vulgare) and one is endemic (C. bursifolia) according to Pignatti (1982). Taxa under study are common species in the Latium Region, with the exception of $C$. bursifolia, which is considered species of biogeographic interest (Conti et al., 2005). The plant material selection was made considering the species ability to grow on poor soils and their potential aesthetic appeal, e.g. flowering or foliage with high ornamental value and morphological diversity (in terms of plant habitus and leaves size). Moreover, all taxa are characterized by abundant achenes production, which can better ensure the persistence of the species. Prior to start the germination tests, seed weight was determined for each taxon weighing 8 replicates of 100 seeds each. The weight of 1000 seeds was $0.169 \mathrm{~g} \pm 0.004$ (Standard error, SE) for C. bursifolia, $0.726 \mathrm{~g} \pm$ 0.014 (SE) for H. radicata, $0.737 \mathrm{~g} \pm 0.009$ (SE) for $P$. hieracioides, $0.342 \mathrm{~g} \pm 0.005$ (SE) for $R$. picroides, $5.694 \mathrm{~g} \pm 0.040(\mathrm{SE})$ for T. pratensis, $0.786 \mathrm{~g} \pm 0.009$ (SE) for M. vulgare, $1.056 \mathrm{~g} \pm$ 0.005 (SE) for P. laciniata.

\section{Germination tests}

Achenes were cleaned from impurities and stored in plastic vials at room temperature and darkness until trials were carried out. Germination tests were performed starting within three months from achenes collection. The experiments were conducted using $15 \mathrm{~cm}$ parafilm-sealed Petri dishes on filter paper moistened with distilled water. In each Petri dish, germination ability was tested on 100 seeds and repeated four times for each species. Different pre-treatments were applied in order to enhance seed germination: i) chilling $\left(5^{\circ} \mathrm{C}\right.$ in darkness and moist conditions for 12 days); ii) mechanical scarification using silica sand previously put in the oven at $85^{\circ} \mathrm{C}$ for $1 \mathrm{~h}$; iii) soaking in gibberellic acid $\left(\mathrm{GA}_{3}\right)$ at a rate of $200 \mathrm{ppm}$ for $10 \mathrm{~min}$; iv) soaking in a $1 \%$ sodium hypochlorite solution $(\mathrm{NaClO})$ for 10 minutes and then washing with distilled water; v) filter papers soaked in a $0.2 \%$ potassium nitrate $\left(\mathrm{KNO}_{3}\right)$ solution.

Petri dishes with untreated or pre-treated seeds were incubated in a climatised cabinet both in light and dark conditions at three different constant temperatures $\left(15,20\right.$ and $\left.25^{\circ} \mathrm{C}\right)$ at least for 30 days and until no further germination occurred after 7 days. White light was produced by neon fluorescent lamps, while dark conditions were obtained by wrapping the dishes with aluminium foil. During the light incubation the photoperiod was $12 \mathrm{~h} / 12 \mathrm{~h}$ (light/dark respectively), and light was regulated at the intensity of $80-\mu \mathrm{mol} \mathrm{m} \mathrm{m}^{-2} \mathrm{~s}^{-1}$. Germination percentage was determined counting germinated achenes. Achenes were considered germinated when the radicle length was $1 \mathrm{~mm}$. After each count, germinated achenes were removed to avoid a possible chance of being counted again.

Time to reach $50 \%$ germination $\left(\mathrm{T}_{50}\right)$ was calculated according to the following formula (Farooq et al., 2005):

$$
T_{50}=t_{i}+\frac{\left(\frac{\mathrm{N}}{2}-n_{i}\right)\left(t_{\mathrm{j}}-t_{i}\right)}{\left(n_{j}-n_{i}\right)}
$$

where $\mathrm{N}$ is the final number of germinating seeds and $\mathrm{n}_{\mathrm{j}}$ and $\mathrm{n}_{\mathrm{i}}$ are the cumulative number of seeds germinated by adjacent counts at times $t_{j}$ and $t_{i}$, respectively, when $n_{i}<N / 2<n_{j}$.

\section{Field experiment}

The field study was conducted for six out of the seven taxa under study, because of the scarce availability of $R$. picroides' achenes. The research was carried out from November 2006 to November 2008 at the Experimental Farm of the University of Tuscia located in Viterbo, Italy (lat. $42^{\circ} 26^{\prime} \mathrm{N}$, long. $12^{\circ} 04^{\prime} \mathrm{E}$, altitude $310 \mathrm{~m}$ a.s.1.) on a neutral sandy loam soil with an organic matter content of $2.2 \%$. The experimental site is characterized by a Mediterranean climate with mean annual maximum and minimum temperatures of 19 and $8^{\circ} \mathrm{C}$, respectively, and annual rainfall of $743 \mathrm{~mm}$. Meteorological data were obtained from a station located at $100 \mathrm{~m}$ from the experimental field. Annual precipitation varied considerably from year to year during the study. In 2007 very low annual rainfall occurred $(475 \mathrm{~mm})$. On the contrary, in 2008 rainfall was abundant and above the long term average (1205 $\mathrm{mm} \mathrm{vs}$ $743 \mathrm{~mm}$ ). In general, drought was experienced during summer from July to August in both years.

A randomized block design consisting of $2 \times 1 \mathrm{~m}$ rainfed plot for each taxon with three replicates was used. The soil was tilled and sown on 15 November 2006, with different seeding rates 
depending on the achenes dimension, plants size and expected mortality (Pons, 1991; Bischoff et al., 2006): 4173 seeds $\mathrm{m}^{-2}$ for C. bursifolia, 1583 seeds $\mathrm{m}^{-2}$ for $H$. radicata, 1085 seeds $\mathrm{m}^{-2}$ for $P$. hieracioides, 360 seeds $\mathrm{m}^{-2}$ for $T$. pratensis, 5851 seeds $\mathrm{m}^{-2}$ for M. vulgare, 1676 seeds $\mathrm{m}^{-2}$ for $P$. laciniata. No pre-germination treatment, watering, fertilising or pesticides were applied.

Cumulative seedling emergence was monitored for 6 months by counting each time all the seedlings visible above ground level in a $0.2 \times 0.2 \mathrm{~m}^{2}$ sampling area. To allow an evaluation of the ability to persist, plant density for each species was registered, by counting plants on the above-mentioned sampling area, two years after sowing. First flowering was determined as the opening of first flower or inflorescence (e.g. Asteraceae species), while the end of flowering as the dehiscence of the last flower or inflorescence.

The flowering duration, expressed as number of days, was recorded from the first flowering to the end of flowering for each taxon in each year. At the peak of flowering, 10 plants were selected randomly from each plot and the number of inflorescences per plant was determined. During the fructification, when plants dimension reached its maximum, the height of taxa was recorded by measuring 10 random plants in each plot. After fructification, 10 infructescences were harvested randomly from each plot and the achenes were manually counted.

\section{Statistical analysis}

Statistical analysis was carried out using R 2.4.0 software (RCORE, 2006). A one-way ANOVA was performed for each taxon to test the effectiveness of dormancy-breaking treatments within each incubation condition (temperature and photoperiod). Two-way ANOVA, with species and year as factors, was performed to analyse the data gathered in the field such as flowering duration, inflorescences per plant, achenes per infructescence and plant height. Threeway ANOVA was used to study the effect of the species, temperature and light conditions on final germination of untreated seeds. Means were separated by the Fisher's least significance difference (LSD) test at the $95 \%$ probability level. All percentage values were arcsine square root transformed before analysis to normalize the variance and back transformed for presentation.

\section{Results}

\section{Seed germination test}

In general, lowest incubation temperature $\left(15^{\circ} \mathrm{C}\right)$ was more favourable to germination of untreated seeds as compared to high- est one $\left(25^{\circ} \mathrm{C}\right)$. Particularly, at $25^{\circ} \mathrm{C}$ the germination of $C$. bursifolia, $P$. hieracioides and $T$. pratensis was significantly lower than that at $15^{\circ} \mathrm{C}$ both under dark and light conditions (Table 1). On the contrary, $M$. vulgare was the only species which did not germinate at $15^{\circ} \mathrm{C}$ and constantly showed a final germination rate lower than $20 \%$. Reichardia picroides showed higher germination values than $M$. vulgare but never exceeding $50 \%$, both under dark and light conditions. With the exception of $M$. vulgare, all the species were photo-dependent. This feature was significant for $C$. bursifolia at 15 and $20^{\circ} \mathrm{C}, \mathrm{H}$. radicata at 20 and $25^{\circ} \mathrm{C}, P$. hieracioides at 15 and $20^{\circ} \mathrm{C}$ and $P$. laciniata at all tested temperatures. For a given temperature, germination of taxa in dark condition was significantly affected by dormancy-breaking treatments, with the exception of M. vulgare. Conversely, under light condition (12 h/12 h photoperiod) seed treatment was less effective, especially at 15 and $20^{\circ} \mathrm{C}$ (Table 2). Chilling was effective for $H$. radicata and $P$. hieracioides both at $25^{\circ} \mathrm{C}$ under dark conditions. Treating seeds with $\mathrm{GA}_{3}$ was particularly effective for $C$. bursifolia at $25^{\circ} \mathrm{C}$ under light conditions and $15^{\circ} \mathrm{C}$ in darkness, $R$. picroides at relatively low temperatures and $M$. vulgare at all tested temperatures with the exception of $15^{\circ} \mathrm{C}$ under dark conditions. The chemical oxidation of germination inhibitors, obtained by using $\mathrm{KNO}_{3}$, was effective only under dark conditions for C. bursifolia at $25^{\circ} \mathrm{C}$ and P. laciniata at $20^{\circ} \mathrm{C}$. Conversely, the use of $\mathrm{NaClO}$ never improved significantly seed germination as compared to control. Finally, scarification significantly improved germination of $R$. picroides and $T$. pratensis both at $25^{\circ} \mathrm{C}$ and in darkness, even though for this latter species the $\mathrm{T}_{50}$ was significantly prolonged.

$\mathrm{T}_{50}$ ranged from 1.5 days for $T$. pratensis seeds treated with chilling in light condition at $15^{\circ} \mathrm{C}$ to 22.5 days for $M$. vulgare seeds treated with chilling in dark condition at $15^{\circ} \mathrm{C}$ (Table 3). In gener$\mathrm{al}$, the higher the temperature, the higher the $\mathrm{T}_{50}$ was. This trend was statistically significant for $C$. bursifolia and $T$. pratensis $(\mathrm{R}=0.88$ and 0.81 , respectively, $\mathrm{P}<0.05)$. As compared to control, dormancy breaking treatments significantly reduced $\mathrm{T}_{50}$ just in few occasions such as for $H$. radicata at $25^{\circ} \mathrm{C}$ (chilling in darkness), $15^{\circ} \mathrm{C}$ and $20^{\circ} \mathrm{C}$ (chilling under light), $R$. picroides at $25^{\circ} \mathrm{C}$ (scarification in darkness) and $20^{\circ} \mathrm{C}\left(\mathrm{GA}_{3}\right.$ under light), $P$. laciniata at $25^{\circ} \mathrm{C}\left(\mathrm{GA}_{3}\right.$ under light), and $P$. hieracioides at 20 and $25^{\circ} \mathrm{C}$ (chilling under light and dark conditions, respectively).

\section{Seedling emergence}

Three out of six species started to emerge within one month from sowing (Figure 1). Particularly, first seedlings were detected 15, 22 and 35 days after sowing for $C$. bursifolia, P. hieracioides and $T$. pratensis, respectively. On the contrary, $H$. radicata, $M$. vul-

Table 1. Germination (GERM) of untreated seeds at different constant incubation temperatures $\left(15,20\right.$ and $\left.25^{\circ} \mathrm{C}\right)$ under light $(12 \mathrm{~h} / 12$ h photoperiod) and dark conditions.

\begin{tabular}{|c|c|c|c|c|c|c|}
\hline & $\begin{array}{c}15^{\circ} \mathrm{C} \\
\text { GERM }(\%)\end{array}$ & $\begin{array}{c}\text { Dark } \\
20^{\circ} \mathrm{C} \\
\text { GERM (\%) }\end{array}$ & $\begin{array}{c}25^{\circ} \mathrm{C} \\
\text { GERM (\%) }\end{array}$ & $\begin{array}{c}15^{\circ} \mathrm{C} \\
\text { GERM }(\%)\end{array}$ & $\begin{array}{c}\text { Light } \\
20^{\circ} \mathrm{C} \\
\text { GERM (\%) }\end{array}$ & $\begin{array}{c}25^{\circ} \mathrm{C} \\
\text { GERM }(\%)\end{array}$ \\
\hline C. bursifolia & $75.0^{\mathrm{eg}}$ & $65.3^{\mathrm{gi}}$ & $38.3^{1 \mathrm{~m}}$ & $89.0^{\mathrm{cd}}$ & $94.0^{\mathrm{bc}}$ & $46.0^{\mathrm{km}}$ \\
\hline H. radicata & $84.8^{\mathrm{de}}$ & $60.0^{\mathrm{hk}}$ & $69.0^{\mathrm{fh}}$ & $75.3^{\mathrm{eg}}$ & $75.3^{e g}$ & $82.5^{\mathrm{de}}$ \\
\hline M. vulgare & Op & $13.3^{\mathrm{n}}$ & $19.3^{\mathrm{n}}$ & Op & $0 \mathrm{p}$ & $5.8^{\circ}$ \\
\hline P. hieracioides & $63.8^{\mathrm{gj}}$ & $52.0^{\text {il }}$ & $38.4^{\mathrm{lm}}$ & $79.0^{\text {ef }}$ & $76.0^{\mathrm{eg}}$ & $46.1^{\mathrm{km}}$ \\
\hline P. laciniata & $68.3^{\mathrm{fh}}$ & $64.1^{\mathrm{gi}}$ & $69.3^{\mathrm{fh}}$ & $100^{\mathrm{a}}$ & $94.2^{\mathrm{bc}}$ & $100^{\mathrm{a}}$ \\
\hline R. picroides & $36.5^{\mathrm{m}}$ & $15.4^{\mathrm{n}}$ & $44.0^{\mathrm{lm}}$ & $50.0^{\mathrm{jm}}$ & $17.0^{\mathrm{n}}$ & $46.0^{\mathrm{km}}$ \\
\hline T. pratensis & $100^{\mathrm{a}}$ & $100^{\mathrm{a}}$ & $38.41^{\mathrm{m}}$ & $100^{\mathrm{a}}$ & $98.0^{\mathrm{ab}}$ & $46.1^{\mathrm{km}}$ \\
\hline
\end{tabular}

Different letters denote statistically significant differences $(\mathrm{P}<0.05)$ by the three-way ANOVA post hoc test (species $\times$ temperatures $\times$ photoperiod). 
gare, and P. laciniata emerged simultaneously 121 days after sowing on March $16^{\text {th }}$. Seedling emergence of the first group of species showed an initial peak (about 30\% for C. bursifolia, 20\% for $P$. hieracioides and $25 \%$ for $T$. pratensis), while the spring-emerging species highlighted a more gradual pattern with very low seedling emergence values $(<5 \%)$ if the initial seeding rate is considered. Anyway, six months after sowing, all taxa reached a stable population, which ranged from 42 plants $\mathrm{m}^{-2}$ for $P$. laciniata to 833 plants $\mathrm{m}^{-2}$ for $C$. bursifolia. Two years after sowing, plant densities dramatically decreased for $T$. pratensis (20 plants $\mathrm{m}^{-2}, 5.5 \%$ of the initial seeding rate), $P$. laciniata ( 8 plants $\mathrm{m}^{-2}, 0.5 \%$ of the initial seeding rate), $M$. vulgare (26 plants $\mathrm{m}^{-2}, 0.4 \%$ of the initial seeding rate), and $P$. hieracioides ( 15 plants $\mathrm{m}^{-2}, 1.4 \%$ of the initial seeding rate), slightly dropped for $C$. bursifolia ( 630 plants $\mathrm{m}^{-2}, 15 \%$ of the initial seeding rate) and remained unchanged for $H$. radicata $(60$ plants $\mathrm{m}^{-2}, 3.8 \%$ of the initial seeding rate).

\section{Flowering features and seed production}

The species greatly differed in flowering dates and duration, showing a blooming calendar from the end of April to middle November in 2007 and to middle October in 2008 (Figure 2). The flowering stage lasted significantly more in 2007 than 2008 for $C$. bursifolia (145 vs 139 days), P. hieracioides (135 vs 100 days) and M. vulgare (55 vs 47 days). Conversely, H. radicata and T. pratensis

Table 2. Germination (GERM) of seeds treated with the most effective dormancy-breaking treatment (DBT), and related difference with untreated seeds germination $(\triangle$ GERM) at different constant incubation temperatures under light (12 h/12 h photoperiod) and dark conditions.

\begin{tabular}{|c|c|c|c|c|c|c|c|c|c|c|c|c|c|c|c|c|c|}
\hline & $\mathrm{DB}$ & $\begin{array}{l}15^{\circ} \mathrm{C} \\
\text { GERM } \\
(\%)\end{array}$ & $\begin{array}{c}\Delta \\
\text { GERM } \\
(\%)\end{array}$ & DBT & $\begin{array}{c}\text { Dark } \\
20^{\circ} \mathrm{C} \\
\text { GERM } \\
(\%)\end{array}$ & $\begin{array}{c}\Delta \\
\text { GERM } \\
(\%)\end{array}$ & DBT & $\begin{array}{c}25^{\circ} \mathrm{C} \\
\text { GERM } \\
(\%)\end{array}$ & $\begin{array}{c}\Delta \\
\text { GERM } \\
(\%)\end{array}$ & DBT & $\begin{array}{c}15^{\circ} \mathrm{C} \\
\text { GERM } \\
(\%)\end{array}$ & $\begin{array}{c}\Delta \\
\text { GERM } \\
(\%)\end{array}$ & DBT & $\begin{array}{l}\text { Light } \\
20^{\circ} \mathrm{C} \\
\text { GERM } \\
(\%)\end{array}$ & $\begin{array}{c}\Delta \\
\text { GERM } \\
(\%)\end{array}$ & DBT & \begin{tabular}{c}
$25^{\circ} \mathrm{C}$ \\
\multicolumn{1}{c}{$\Delta$} \\
GERM GERM \\
$(\%) \quad(\%)$
\end{tabular} \\
\hline C. bursifolia & $\mathrm{GA}_{3}$ & 94.2 & $+19.2 *$ & nt & - & - & $\mathrm{KNO}_{3}$ & 53.8 & $+15.5^{*}$ & $\mathrm{GA}_{3}$ & 94.2 & $+5.2 \mathrm{~ns}$ & $\mathrm{GA}_{3}$ & 100 & $+6.0 \mathrm{~ns}$ & $\mathrm{GA}_{3}$ & $90.4+44.4^{*}$ \\
\hline H. radicata & Chill. & 32.6 & $-52.2^{*}$ & nt & - & - & Chill. & 91.0 & $+22.0^{*}$ & Chill. & 63.5 & $-11.8^{*}$ & Chill. & 80.8 & $+5.5^{*}$ & nt & - \\
\hline M. vulgare & Chill. & 3.8 & $+3.8 \mathrm{~ns}$ & $\mathrm{GA}_{3}$ & 92.3 & $+79.0^{*}$ & $\mathrm{GA}_{3}$ & 50.0 & $+30.7 *$ & $\mathrm{GA}_{3}$ & 75.0 & $+75.0^{*}$ & $\mathrm{GA}_{3}$ & 73.1 & $+73.1^{*}$ & $\mathrm{GA}_{3}$ & $92.3+86.5^{*}$ \\
\hline P. hieracioides & nt & - & - & nt & - & - & Chill. & 84.0 & $+45.6^{*}$ & $\mathrm{GA}_{3}$ & 88.5 & $+9.5 n s$ & Chill. & 84.6 & $+8.6 \mathrm{~ns}$ & nt & - \\
\hline P. laciniata & nt & - & - & $\mathrm{KNO}_{3}$ & 100 & $+35.9^{*}$ & $\mathrm{KNO}_{3}$ & 21.1 & $-48.2^{*}$ & $\mathrm{NaClO}$ & 100 & Ons & Scar. & 96.2 & $+2.0 \mathrm{~ns}$ & $\mathrm{GA}_{3}$ & 100 \\
\hline R. picroides & nt & - & - & $\mathrm{GA}_{3}$ & 34.6 & $+19.2^{*}$ & Scar. & 75.5 & $+31.5^{*}$ & $\mathrm{GA}_{3}$ & 65.4 & $+15.4^{*}$ & $\mathrm{GA}_{3}$ & 38.4 & $+21.4^{*}$ & nt & - \\
\hline T. pratensis & nt & - & - & nt & - & - & Scar. & 100 & $+61.6^{*}$ & Chill. & 100 & Ons & $\mathrm{NaClO}$ & 98.0 & Ons & nt & - \\
\hline
\end{tabular}

*DBT Significantly different from control at $\mathrm{P}<0.05$; ns, DBT not significant; nt, DBT not tested.

Table 3. Means of $\mathrm{T}_{50}$ of untreated seeds and treated with the most effective dormancy-breaking treatment (DBT), at different constant incubation temperatures under light $(12 \mathrm{~h} / 12 \mathrm{~h}$ photoperiod) and dark conditions. Fisher's LSD was calculated within each temperature regime and species.

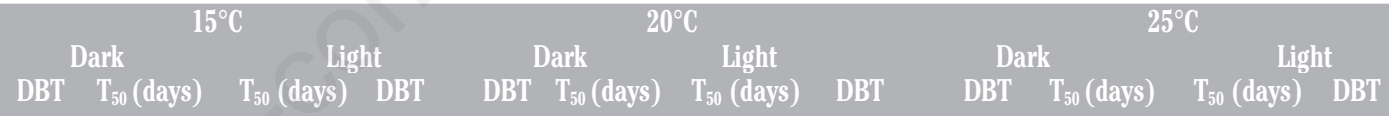

\begin{tabular}{|c|c|c|c|c|c|c|c|c|c|c|c|c|c|}
\hline C. bursifolia & $\begin{array}{l}\text { Untreated } \\
\text { Treated } \\
\text { LSD }\end{array}$ & $\mathrm{GA}_{3}$ & $\begin{array}{l}2.0 \\
1.6\end{array}$ & $\begin{array}{r}2.8 \\
5.0 \\
1.1^{* * *}\end{array}$ & $\mathrm{GA}_{3}$ & nt & $\begin{array}{c}5.2 \\
-\end{array}$ & $\begin{array}{r}4.9 \\
3.9 \\
1.0 * * *\end{array}$ & $\mathrm{GA}_{3}$ & $\mathrm{KNO}_{3}$ & $\begin{array}{l}10.3 \\
18.3\end{array}$ & $\begin{array}{r}9.0 \\
3.8^{* *}\end{array}$ & $\mathrm{GA}_{3}$ \\
\hline H. radicata & $\begin{array}{l}\text { Untreated } \\
\text { Treated } \\
\text { LSD }\end{array}$ & Chill. & $\begin{array}{l}1.6 \\
2.7\end{array}$ & $\begin{array}{l}4.1 \\
2.4 \\
0.5^{* * *}\end{array}$ & Chill. & nt & $\begin{array}{c}5.1 \\
-\end{array}$ & $\begin{array}{r}4.5 \\
1.7 \\
0.5^{* * *}\end{array}$ & Chill. & Chill. & $\begin{array}{l}6.3 \\
1.6\end{array}$ & $\begin{array}{r}1.9 \\
4.6^{* * *}\end{array}$ & nt \\
\hline M. vulgare & $\begin{array}{l}\text { Untreated } \\
\text { Treated } \\
\text { LSD }\end{array}$ & Chill. & $\begin{array}{c}- \\
22.5\end{array}$ & $\begin{array}{c}\overline{11.8} \\
3.2^{* * *}\end{array}$ & $\mathrm{GA}_{3}$ & $\mathrm{GA}_{3}$ & $\begin{array}{l}8.3 \\
6.6\end{array}$ & $2.4^{* * *}{ }^{-}$ & $\mathrm{GA}_{3}$ & $\mathrm{GA}_{3}$ & $\begin{array}{l}9.0 \\
7.6\end{array}$ & $\begin{array}{r}17.3 \\
13.5 \\
4.0 * * *\end{array}$ & $\mathrm{GA}_{3}$ \\
\hline P. hieracioides & $\begin{array}{l}\text { Untreated } \\
\text { Treated } \\
\text { LSD }\end{array}$ & nt & $\begin{array}{c}3.9 \\
-\end{array}$ & $\begin{array}{r}4.7 \\
4.5 \\
0.3^{* * *}\end{array}$ & $\mathrm{GA}_{3}$ & nt & $\begin{array}{c}5.0 \\
-\end{array}$ & $\begin{array}{r}7.4 \\
1.7 \\
0.9 * * *\end{array}$ & Chill. & Chill. & $\begin{array}{l}3.5 \\
1.6\end{array}$ & $\begin{array}{c}3.4 \\
-\end{array}$ & nt \\
\hline P. laciniata & $\begin{array}{l}\text { Untreated } \\
\text { Treated } \\
\text { LSD }\end{array}$ & nt & $\begin{array}{c}8.6 \\
-\end{array}$ & $\begin{array}{r}3.0 \\
3.4 \\
1.6^{* * *}\end{array}$ & $\mathrm{NaClO}$ & $\mathrm{KNO}_{3}$ & $\begin{array}{l}3.5 \\
3.9\end{array}$ & $\begin{array}{r}4.6 \\
2.9 \\
2.4^{* * *}\end{array}$ & Scar. & $\mathrm{KNO}_{3}$ & $\begin{array}{c}5.4 \\
21.4\end{array}$ & $\begin{array}{r}4.9 \\
1.7 \\
1.1^{* * *}\end{array}$ & $\mathrm{GA}_{3}$ \\
\hline R. picroides & $\begin{array}{l}\text { Untreated } \\
\text { Treated } \\
\text { LSD }\end{array}$ & nt & $\begin{array}{c}4.8 \\
-\end{array}$ & $\begin{array}{r}4.5 \\
5.9 * *\end{array}$ & $\mathrm{GA}_{3}$ & $\mathrm{GA}_{3}$ & $\begin{array}{l}9.0 \\
7.5\end{array}$ & $\begin{array}{r}9.4 \\
4.6 \\
1.9 * * *\end{array}$ & $\mathrm{GA}_{3}$ & Scar. & $\begin{array}{c}15.2 \\
2.7\end{array}$ & $\begin{array}{r}4.4 \\
- \\
1.9 * * *\end{array}$ & nt \\
\hline T. pratensis & $\begin{array}{l}\text { Untreated } \\
\text { Treated } \\
\text { LSD }\end{array}$ & nt & $\begin{array}{c}2.1 \\
-\end{array}$ & $\begin{array}{r}3.5 \\
1.5 \\
0.7^{* * *}\end{array}$ & Chill. & nt & $\begin{array}{c}3.0 \\
-\end{array}$ & $\begin{array}{r}4.8 \\
4.5 \\
1.1 * * * \\
\end{array}$ & $\mathrm{NaClO}$ & Scar. & $\begin{array}{c}7.5 \\
15.3\end{array}$ & $\begin{array}{r}12.0 \\
2.2^{* * *}\end{array}$ & nt \\
\hline
\end{tabular}

Significance of the ANOVA: ${ }^{* *} \mathrm{P}<0.001,{ }^{*} \mathrm{P}<0.01,{ }^{*} \mathrm{P}<0.05$; ns, not significant; nt, not tested. 
showed a prolonged flowering period in 2008 (153 and 71 days, respectively) than 2007 (110 and 35 days, respectively), while flowering dynamic of $P$. laciniata substantially remained unchanged between years (48 days in 2007 and 47 days in 2008). With respect to precocity, C. bursifolia was recorded as early-blooming species, while the latest ones were $P$. hieracioides and $P$. laciniata.

A significant species $\times$ year interaction $(\mathrm{P}<0.001)$ was found analysing both the number of inflorescences per plant and achenes per infructescence. All the species showed an increased number of inflorescences in 2008 compared to 2007 but it was statistically significant only for $H$. radicata, $M$. vulgare and $P$. hieracioides (Figure 3). Picris hieracioides produced the highest number of inflorescences in both years, whilst $T$. pratensis the lowest one. Averaged over two years, $H$. radicata and $M$. vulgare displayed good ornamental potential, producing more than 60 inflorescences per plant. On the contrary, C. bursifolia and P. laciniata were poor flowering species, with just 26 inflorescences produced per plant. With the exception of $M$. vulgare and P. laciniata, no significant

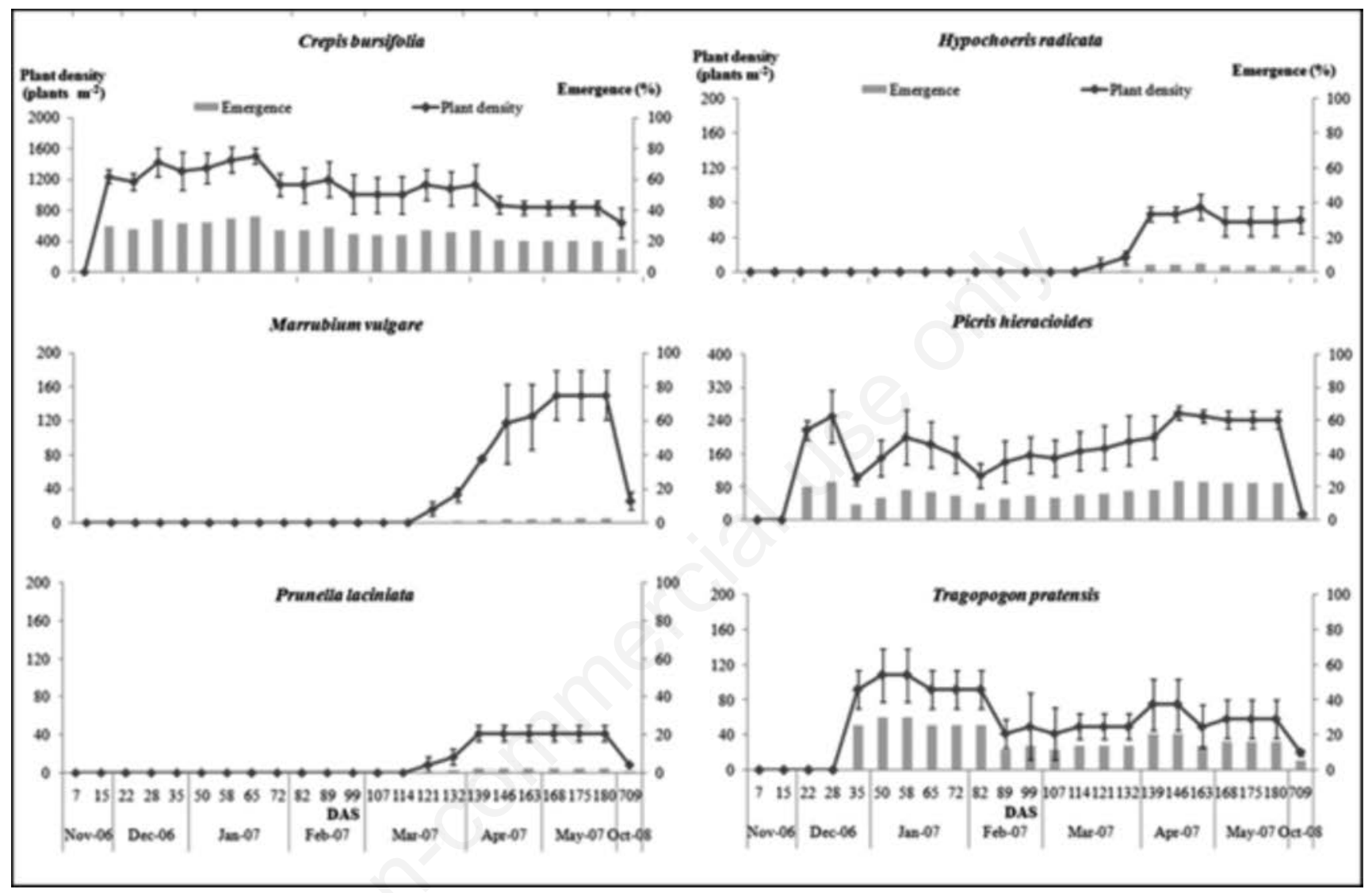

Figure 1. Emergence dynamics of 6 wildflower species (mean value \pm standard errors, $n=4 ;$ where absent, bars fall within symbols). Time of emergence is showed as days after sowing (DAS).

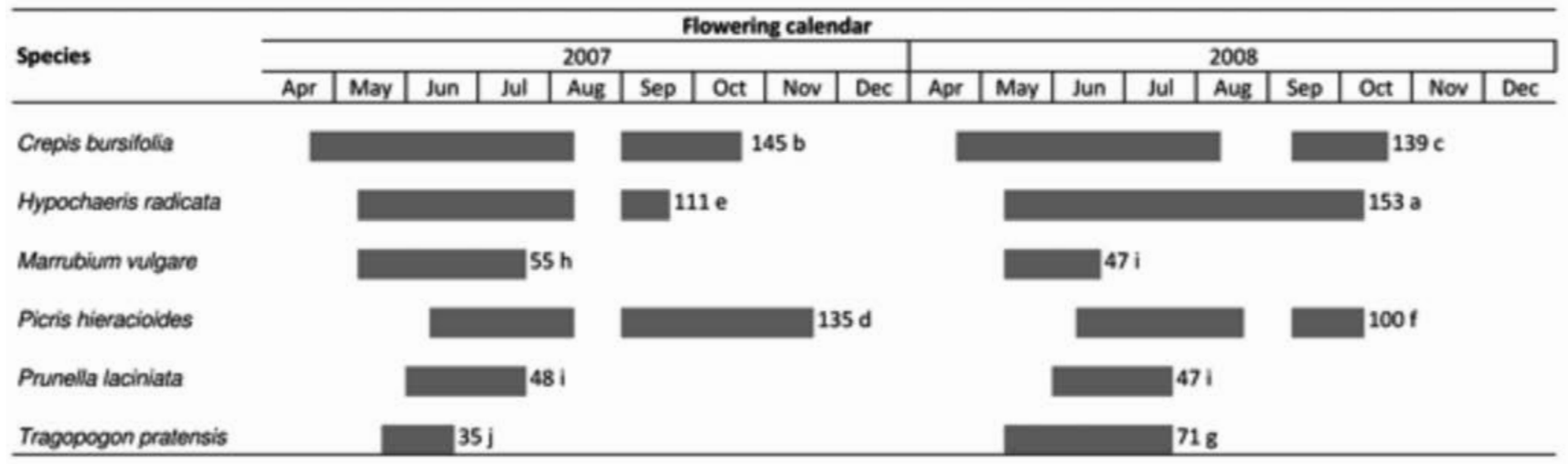

Figure 2. Flowering duration with ordinal number of bloom days for 6 wildflower species in two growing seasons (2007 and 2008$)$. Means having different letters are significantly different $(P<0.05)$. 
differences were found between 2007 and 2008 seed production per infructescence. Moreover, M. vulgare and P. laciniata was always the top yielding species with more than 100 achenes per infructescence produced as 2-years mean.

\section{Plant height}

Plant height significantly differed among the species under study and between years. Averaged over 2 years, the height varied significantly from $13 \mathrm{~cm}$ of C. bursifolia to $95 \mathrm{~cm}$ of $P$. hieracioides (Figure 3). Results pointed out different ranges of height reached by taxa: $C$. bursifolia and $P$. laciniata were the shortest species (up to $31 \mathrm{~cm}, 2$-years mean), M. vulgare and T. pratensis reached medium heights (between 50 and $60 \mathrm{~cm}$ ), H. radicata and $P$. hieracioides were the tallest species reaching 75 and $95 \mathrm{~cm}$, respectively.
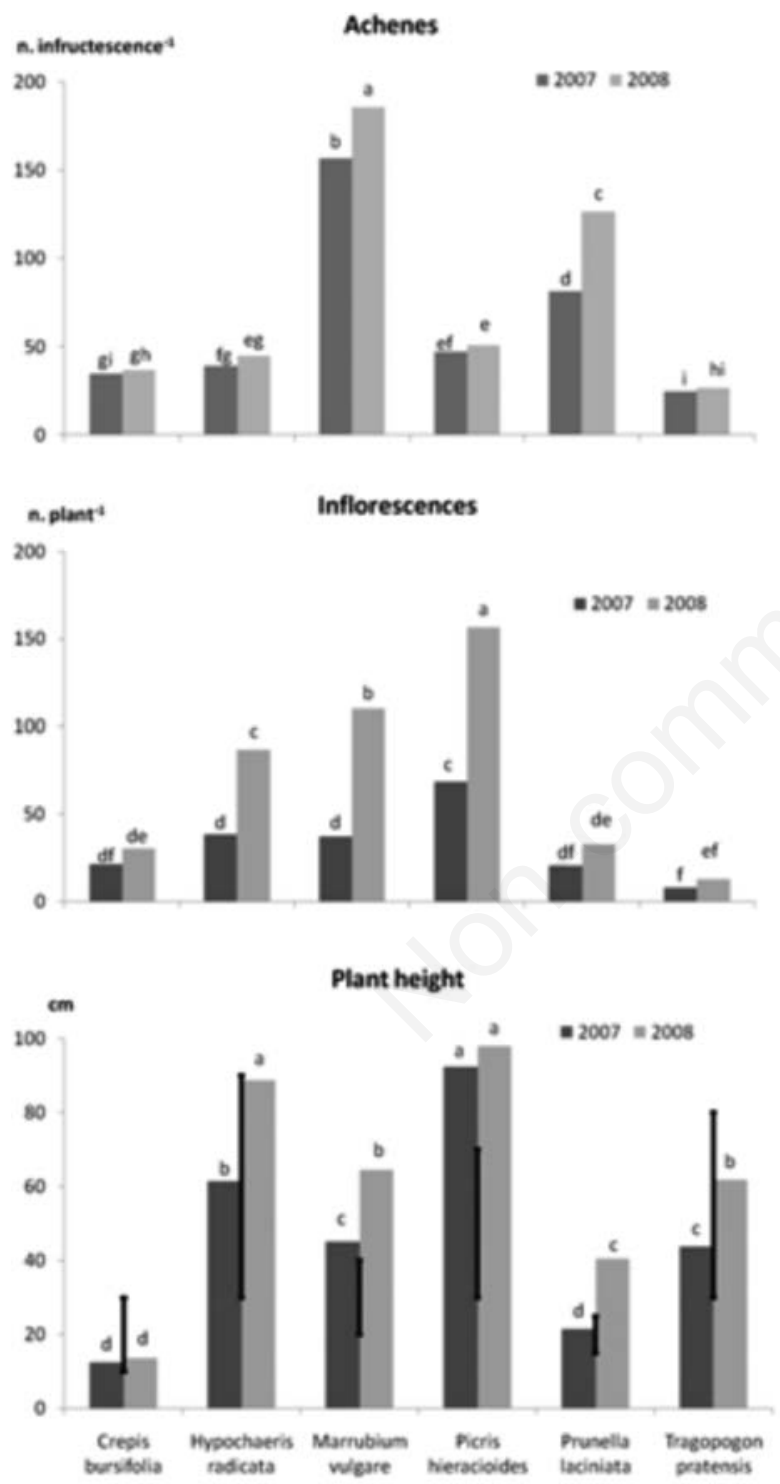

Figure 3. Number of inflorescences per plant, number of achenes per infructescence and plant height of 6 wildflower species in two growing seasons (2007 and 2008). Different letters indicate significant differences according to Fisher's least significance difference (LSD) test $(P<0.05)$. Vertical bars show reference ranges for plant height according to Pignatti (1982).

\section{Discussion}

\section{Seed germination test}

The results on germination test have to be regarded as preliminary, because dormancy level may significantly vary among plant populations and years of seed collection (Beckstead et al., 1996; Schütz and Milberg, 1997; Andersson and Milberg, 1998). Despite this, our findings may provide precious information for those who wish to investigate deeper into the germination ecology of such species.

Generally, the lower incubation temperatures favoured the germination of tested species. The same behaviour in seeds germination ability was observed by other authors that investigated ecophysiological aspects of seed germination in Mediterranean species (Galmés et al., 2006; Luna et al., 2012) and also by Baskin and Baskin (2004b) on some morphologically dormant seeds. Conversely, widely distributed $M$. vulgare proved to be less sensitive to incubation temperature and it constantly showed poor germination rate. This is in agreement with previous studies that have also reported low germination percentage for this species if subjected to constant temperatures (Benvenuti et al., 2001). We found $R$. picroides never overcoming $50 \%$ germination, and this result is consistent with a recent study by Benvenuti and Pardossi (2016) that showed for this species a germination of $42.2 \%$, without dormancy breaking treatments.

In this study, the positive role of light in the germination process of wild species was clearly confirmed for the majority of tested species (Wessonand Wareing, 1969). Other studies indicated light as an important factor controlling the germination of plants (Honda and Katoh, 2007; Luna and Moreno, 2009). Moreover, the dependence of germination on light availability is well-rendered in literature for plants with very small seeds, such as C. bursifolia, confirming the need for light and shallow planting depth for these kind of species (Milberg et al., 2000).

Results from our study showed that tested species benefited from dormancy-breaking treatments in many occasions. Consequently, knowing how to remove dormancy represents a pivotal factor for their cultivation in rural and urban landscapes. This is particularly true for those species such as M. vulgare, $R$. picroides and $P$. hieracioides, which show low germination percentage without dormancy-breaking treatments. The effectiveness of treating seeds with chilling and $\mathrm{GA}_{3}$ suggested the presence of a possible physiological dormancy in some tested taxa. Probably, chilling has the ecological role of stimulating germination during spring, when climatic conditions are most favourable for plant growing (Baskin and Baskin, 2004a). In contrast with other authors (Bretzel et al., 2009; Benvenuti and Pardossi, 2016), soaking seeds in $\mathrm{NaClO}$ was never able to significantly promote germination as compared to control. This finding was probably due to the fact that germination inhibitors are often tolerant to degradation (Halloin, 1983) and the efficacy of $\mathrm{NaClO}$ varies depending on the species.

Since seedling establishment is a key stage in plants' life cycles (Donohue et al., 2010), species with low $\mathrm{T}_{50}$ values could take advantage from earlier emergence to escape competition (Ross and Harper, 1972; Abul-Faith and Bazzaz, 1979; Kalisz, 1986). This is particularly true for C. bursifolia and P. laciniata taking into account their low height.

\section{Seedling emergence and survival of species}

The time of emergence of $C$. bursifolia, $P$. hieracioides and $T$. 
pratensis confirmed the results obtained in growth chamber study under relatively low temperatures. Conversely, the delayed germination of $H$. radicata and $P$. laciniata under field conditions suggested that these species may acquire a secondary dormancy after sowing. A similar behaviour was observed by Winn (1985) for Prunella vulgaris L. in southwestern Michigan.

Some factors in light chamber studies are different from natural conditions and may lead to a higher germination rate and speed (Keller and Kollmann, 1999; Benvenuti and Pardossi, 2016). For example, moisture is constant and optimal, filter paper is sterile and germination inhibitors are probably more effectively washed out. Seedling emergence was generally poor and plant density markedly varied during the study, especially for early-emerging species. The major reason of this variation during autumn and winter appeared to be seedlings mortality caused by both abiotic and biotic stresses such as cold temperatures, soil drought and intraspecific competition (Harper and McNaughton, 1962; White and Harper, 1970; Jorritsma-Wienk et al., 2007). Anyway, two years after sowing, only $C$. bursifolia and $H$. radicata showed a good ability to persist in low-maintenance conditions. Long-term persistence is a key factor for sustainable greening, because low seedling emergence rates and high mortality of both seeds and plants were events well rendered by many authors who investigated the distribution and establishment of natural and cultivated perennials (Friedman and Orshan, 1975; Winn, 1985; Hitchmough, 2000; Thomas and Schrock, 2004). The ability to persist and spread of $C$. bursifolia, was documented also by authors who checked the flora in central Italy over time. Particularly, C. bursifolia was ranked as rare species in 1994 while it became a rarely common species in 2010 (Anzalone, 1994; Anzalone et al., 2010).

\section{Flowering features and seed production}

As herbaceous vegetation is highly seasonal in appearance, there is a need, in the temperate regions, for species which are attractive also in summertime (Dunnett and Hitchmough, 2004). This is particularly true for the Mediterranean environment in which summer heat and drought stress severely limit plant growth. Moreover, another important aesthetic requirement is the duration of flowering to ensure as long a flowering period as possible. The results from our study identified $C$. bursifolia and $H$. radicata both having these crucial features and thus as promising taxa for green areas near to where people live or work.

Moreover, a strong influence of the year on the number of inflorescences was registered for the half of tested species so that it could considerably affect the ornamental value of the species. Generally, the number of inflorescences increased with the age of the plant and this is consistent with other authors that found many perennials showing little flowering during the first years (Dunnett and Hitchmough, 2004).

Disturbed urban sites usually favour quick-growing plants with abundant seed production (Rinehart, 2006). On the contrary, in our study, the species which produced the larger amount of achenes per plant (i.e. M. vulgare and P. hieracioides) failed to increase in abundance. This was probably due to the poor ability of these two species to establish and spread when a vegetation already exists, as previously found by other authors in arid environments (Andrew and Lange, 1986; Sans et al., 2002, 1998).

\section{Plant height}

Most of the species exceeded the upper limit of the height found in literature for natural communities (Pignatti, 1982). This finding was probably due to the specific field conditions (i.e. plots planted in monoculture, sowing on bare soil, presence of fertile soil) which are much different from those observed in natural habitats. With the exception of $C$. bursifolia and P. hieracioides, taxa showed significantly higher values in the second year than the first one. This was mostly due to the rainfall abundance registered in 2008 as compared to 2007 when the growing season experienced severe drought.

Plant size affects vegetation dynamics and distribution because of light competition (Schwinning and Weiner, 1999; Moles et al., 2009). Thus, size asymmetry among plants can lead to phenomena of growth suppression of smaller individuals (Hautier et al., 2009). Results from this study may help to characterize the tested species and give directions for their management.

\section{Conclusions}

Our study clearly demonstrates that local seeds need to be tested both for their germination features and field establishment ability prior to mixture and direct use in landscaping projects.

Untreated seeds of $C$. bursifolia, $P$. hieracioides and T. pratensis showed a prompt germination and emergence within one month from sowing, indicating a possible use in autumn planting immediately after the collection of seeds. On the contrary, the high seed dormancy highlighted both under laboratory and field condition by M. vulgare, implies the necessity to use pre-treated seeds $\left(\mathrm{GA}_{3}\right)$ to have high germination rate and speed. The emergence time of $H$. radicata and $P$. laciniata was greatly delayed under natural conditions, suggesting the acquisition of a secondary dormancy, which should be further investigated.

Overall, since durability is a major point of using perennials in sustainable gardening and landscape projects, the only two taxa, which performed well over two-years field experiments were $C$. bursifolia and $H$. radicata. These species were also those, which showed the longest flowering period and the capacity to be attractive also throughout the summer months. For its small size, C. bursifolia may be profitably used in residential greening, school gardens and parks, while $H$. radicata probably is better suited to green spaces not usually visited by people (e.g. roadsides, slopes, wildflower strips, etc.).

Although more effort is necessary to refine and enrich data on local population and other species (e.g. annuals), the specific morphometric features and eco-physiological traits recorded in this study, represent an important novel source of information for creating and maintaining wildflower meadows in a Mediterranean environment, especially when a sustainable approach is required.

\section{References}

Abul-Faith HA, Bazzaz FA, 1979. The Biology of Ambrosia trifida L. II. Germination, emergence, growth and survival. New Phytol. 83:817-27.

Andersson L, Milberg P, 1998. Variation in seed dormancy among mother plants, populations and years of seed collection. Seed Sci. Res. 8:29-38.

Andrew MH, Lange RT, 1986. Development of a new piosphere in arid chenopod shrubland grazed by sheep. 2. Changes to the vegetation. Aust. J. Ecol. 11:411-24.

Anzalone B, 1994. Prodromo della flora romana. Parte Prima: Pteridophyta, Gymnospermae, Angiospermae, Dicotyledones. 
Ann. Bot. 52:1-81

Anzalone B, Iberite M, Lattanzi E, 2010. La flora vascolare del Lazio. Inf. Bot. Ital. 42:187-317.

Baskin CC, Baskin JM, 2004a. Germinating seeds of wildflowers, an ecological perspective. HortTechnol. 14:467-73.

Baskin JM, Baskin CC, 2004b. A classification system for seed dormancy. Seed Sci. Res. 14.

Beckstead J, Meyer SE, Allen PS, 1996. Bromus tectorum seed germination: between-population and between-year variation. Can. J. Bot. 74:875-82.

Benvenuti S, Andolfi L, Macchia M, 2001. Light and temperature dependence for germination and emergence of white horehound (Marrubium vulgare L.) seeds. Seed Technol. 23:138-44.

Benvenuti S, Pardossi A, 2016. Germination ecology of nutraceutical herbs for agronomic perspectives. Eur. J. Agron. 76:118-29.

Bischoff A, Vonlanthen B, Steinger T, Müller-Schärer H, 2006. Seed provenance matters - Effects on germination of four plant species used for ecological restoration. Basic Appl. Ecol. 7:347-59.

Braman SK, Pendley AF, Corley W, 2002. Influence of commercially available wildflower mixes on beneficial arthropod abundance and predation in turfgrass. Environ. Entomol. 31:564-72.

Bretzel F, Malorgio F, Paoletti L, Pezzarossa B, 2012. Response of sowed, flowering herbaceous communities suitable for anthropic Mediterranean areas under different mowing regimes. Landsc. Urban Plan. 107:80-8.

Bretzel F, Pezzarossa B, Benvenuti S, Bravi A, Malorgio F, 2009. Soil influence on the performance of 26 native herbaceous plants suitable for sustainable Mediterranean landscaping. Acta Oecol. 35:657-63.

Bretzel F, Vannucchi F, Romano D, Malorgio F, Benvenuti S, Pezzarossa B, 2016. Wildflowers: from conserving biodiversity to urban greening - a review. Urban For. Urban Green. 20:428-36.

Coleman JL, Rollet-crocker K, Lewis D, Lindstrom J, 2002. Native plants : the preservation and restoration of native plants in designed landscapes in Northwest Arkansas. Inq. Univ. Arkansas 3:5-18.

Conti F, Abbate G, Alessandrini A, Blasi C, 2005. An annotated checklist of the Italian vascular flora. Palombi ed., Roma, Italy.

De Mei M, Di Mauro M, 2006. Study of some characteristic Mediterranean vegetation species best suited for renaturalization of terminal-phase municipal solid waste (MSW) landfills in Puglia (Southern Italy). Acta Oecol. 30:78-87.

Donohue K, Rubio de Casas R, Burghardt L, Kovach K, Willis CG, 2010. Germination, postgermination adaptation, and species ecological ranges. Annu. Rev. Ecol. Evol. Syst. 41:293-319.

Dunnett N, Hitchmough J, 2004. The dynamic landscape: design, ecology and management of naturalistic urban planting. Taylor \&Francis, New York, USA.

Farooq M, Basra SMA, Ahmad N, Hafeez K, 2005. Thermal hardening: a new seed vigor enhancement tool in rice. J. Integr. Plant Biol. 47:187-93.

Florgård C, 2000. Long-term changes in indigenous vegetation preserved in urban areas. Landsc. Urban Plan. 52:101-6.

Forman RTT, Alexander LE, 1998. Roads and their major ecological effects. Annu. Rev. Ecol. Syst. 29:207-31.

Friedman J, Orshan G, 1975. The distribution, emergence and survival of seedlings of Artemisia Herba-Alba Asso in the Negev Desert of Israel in relation to distance from the adult plants. J. Ecol. 63:627-32.
Galmés J, Medrano H, Flexas J, 2006. Germination capacity and temperature dependence in Mediterranean species of the Balearic Islands. Invest. Agrar. Sist. Recur. For. 15:88-95.

Halloin JM, 1983. Deterioration resistance mechanisms in seeds. Phytopathology 73:335-9.

Harper JL, McNaughton IH, 1962. The comparative biology of closely related species living in the same area VII. interference between individuals in pure and mixed populations of Papaver species. New Phytol. 61:175-88.

Hautier Y, Niklaus P, Hector A, 2009. Competition for light causes plant biodiversity loss after eutrophication. Science 324:636-8.

Hicks DM, Ouvrard P, Baldock KCR, Baude M, Goddard MA, Kunin WE, Mitschunas N, Memmott J, Morse H, Nikolitsi M, Osgathorpe LM, Potts SG, Robertson KM, Scott A V, Sinclair F, Westbury DB, Stone GN, 2016. Food for pollinators: quantifying the nectar and pollen resources of urban flower meadows. PLoS One 11:e0158117.

Hitchmough JD, 2000. Establishment of cultivated herbaceous perennials in purpose-sown native wildflower meadows in south-west Scotland. Landsc. Urban Plan. 51:37-51.

Honda Y, Katoh K, 2007. Strict requirement of fluctuating temperatures as a reliable gap signal in Picris hieracioides var. japonica seed germination. Plant Ecol. 193:147-56.

Jones AT, Evans PR, 1994. A comparison of the growth and morphology of native and commercially obtained continental \{European\} \{Crataegus\} monogyna $\{$ Jacq\}. (hawthorn) at an upland site. Watsonia 20:97-103.

Jongepierová I, Mitchley J, Tzanopoulos J, 2007. A field experiment to recreate species rich hay meadows using regional seed mixtures. Biol. Conserv. 139:297-305.

Jorritsma-Wienk LD, Ameloot E, Lenssen JPM, De Kroon H, 2007. Differential responses of germination and seedling establishment in populations of Tragopogon pratensis (Asteraceae). Plant Biol. 9:109-15.

Kalisz S, 1986. Variable selection on the timing of germination in Collinsia verna (Scrophulariaceae). Evolution (N.Y). 40:479-91.

Karim MN, Mallik AU, 2008. Roadside revegetation by native plants. I. Roadside microhabitats, floristic zonation and species traits. Ecol. Eng. 32:222-37.

Keller M, Kollmann J, 1999. Effects of seed provenance on germination of herbs for agricultural compensation sites. Agric. Ecosyst. Environ. 72:87-99.

Kendle AD, Rose JE, 2000. The aliens have landed! What are the justifications for "native only" policies in landscape plantings? Landsc. Urban Plan. 47:19-31.

Kennedy CEJ, Southwood TRE, 1984. The number of insects associated with British trees a re-analysis. J. Anim. Ecol. 53:455-78.

Lindemann-Matthies P, Bose E, 2007. Species richness, structural diversity and species composition in meadows created by visitors of a botanical garden in Switzerland. Landsc. Urban Plan. 79:298-307

Luna B, Moreno JM, 2009. Light and nitrate effects on seed germination of Mediterranean plant species of several functional groups. Plant Ecol. 203:123-35.

Luna B, Pérez B, Torres I, Moreno JM, 2012. Effects of incubation temperature on seed germination of mediterranean plants with different geographical distribution ranges. Folia Geobot. 47:17-27.

Milberg P, Andersson L, Thompson K, 2000. Large-seeded species are less dependent on light for germination than small-seeded ones. Seed Sci. Res. 10:99-104.

Moles AT, Warton DI, Warman L, Swenson NG, Laffan SW, Zanne AE, Pitman A, Hemmings, F.A., Leishman, M.R., 2009. 
Global patterns in plant height. J. Ecol. 97:923-32.

Nocentini S, 1995. The renaturalization of forest plantations. An experimental trial with Pinus nigra and P. nigra var. laricio on Monte Morello near Florence. Ital. For. Mont. 50:425-35.

Pignatti S, 1982. Flora d'Italia. 3 vols. Edagricole, Bologna, Italy.

Pons TL, 1991. Dormancy, germination and mortality of seeds in a chalk-grassland flora. J. Ecol. 79:765-80.

RCORE TEAM, 2006. R: A language and environment for statistical computing. R Foundation for Statistical Computing, Vienna, Austria.

Rinehart K, 2006. Naturalist's guide to observing nature, 1st edition. ed. Stackpole Books.

Ross MA, Harper JL, 1972. Occupation of biological space during seedling establishment. J. Ecol. 60:77-80.

Ruggeri R, Provenzano ME, Rossini F, 2016. Effect of mulch on initial coverage of four groundcover species for low input landscaping in a Mediterranean climate. Urban For. Urban Green. 19:176-83.

Salisbury A, Armitage J, Bostock H, Perry J, Tatchell M, Thompson K, 2015. Enhancing gardens as habitats for flowervisiting aerial insects (pollinators): Should we plant native or exotic species? J. Appl. Ecol. 52:1156-64.

Sans F, Escarré J, Gorse V, Lepart J, 1998. Persistence of Picris hieracioides populations in old fields: an example of facilitation. Oikos 83:283-92.

Sans F, Escarré J, Lepart J, Hopkins F, 2002. Positive vs. negative interactions in Picris hieracioides L., a mid-successional species of Mediterranean secondary succession. Plant Ecol. 162:109-22.

Schütz W, Milberg P, 1997. Seed dormancy in Carex canescens: regional differences and ecological consequences. Oikos 78:420-8.

Schwinning S, Weiner J, 1998. Mechanisms determining the degree of size asymmetry in competition among plants. Oecologia 113;447-55.

Slattery BE, Reshetiloff K, Zwicker SM, 2003. Native plants for wildlife habitat and conservation landscaping chesapeake bay watershed. U.S. Fish and Wildlife Service.

Thomas AL, Schrock D, 2004. Performance of 67 Native Midwestern U.S. Perennials in a Low-maintenance Landscap. HortTechnol. 14:381-8.

Wesson G, Wareing PF, 1969. The role of light in the germination of naturally occurring populations of buried weed seeds. J. Exp. Bot. 20:402-13.

White J, Harper JL, 1970. Correlated changes in plant size and number in plant populations. J. Ecol. 58:467.

Winn A, 1985. Effects of seed size and microsite on seedling emergence of Prunella vulgaris in four habitats. J. Ecol. 73:831-40.

Worrell R, 1992. A comparison between European continental and British provenances of some British native trees: growth, survival and stem form. Forestry 65:253-80. 